\title{
Exosomes as therapy for cancer
}

\author{
Rocío Retamales-Ortega and María Lorena Oróstica* \\ Centro de Investigación Biomédica (CIB), Facultad de Medicina, Universidad Diego Portales, Santiago, Chile
}

Cancer was the sixth cause of death in 2016 and 18,078,957 people died in 2018 in the world. The leading cause of cancer death is metastasis [1], and it is responsible for $90 \%$ of cancer-related deaths [2]. The incidence of many cancers, as gastrointestinal cancers, still increases worldwide [3], and a tremendous number of patients despite advances in surgical technique, chemotherapy, endoscopic interventions and radiation therapy [4].

It has been proposed that exosomes can be used as biomarkers for cancer and in combination microRNAs (miRs), which trend to be enriched in exosomes $[5,6]$. As a therapeutic target have been proposed different steps in the exosome's biogenesis and, more strikingly, the development of tools that can emulated exosomes that can deliver different molecules, for example shRNAs.

\section{Exosomes}

Exosomes are a group of microvesicles formed by a lipid bilayer and its intraluminal content depends on the cells that produce them, then carries different types of molecules such as RNAs (miR, mRNA, etc.), membrane proteins, metabolites, lipids and DNA $[7,8]$. Its role in cancer has been widely studied and it has been shown that it can promote both tumor development and metastasis [9-11]. In fact, exosomes related to cancer contain oncoproteins such as MET, RAS, EGFR and HIF-1 $\alpha$, which are involved in the processes of proliferation and cell survival [12].

Exosomes play important roles in cancer development like the modification of the tumor microenvironment to benefit tumor growth and survival, and some process as immune system evasion, inducing angiogenesis (to have access to a greater number of resources) [1315], accelerated growth and proliferation, evading programmed cell death, reprogramming the energy metabolism of the cell, and algo processes like migration, invasion, etc $[16,17]$. Another important process where exosomes are involved in is metastasis, which can be lead by a differential expression of proteins of the integrin family on their surface, mediating the exosome accumulation through interaction with the ECM [18]. Cells residing in the site where cancer cells could metastasize capture these exosomes which causes them to alter the tissue organization, stimulating the formation of new vessels, preparing the arrival of circulating tumor cells. Furthermore, metastases in lung and liver were diminished with the blocking of integrins that diminish the uptake of exosomes [18]. Another example of exosome role in metastasis is the association with pathological stages, since exosomal TGF- $\beta 1$ related to lymph nodes metastasis and the ratio of Treg cells in lymph nodes in gastric cancer patients [19].

Exosomes have a pleiotropic role, where they can regulate not only intercellular communication between cancer cells but also act as potential mediator for educating the Pre-Metastatic Niche (PMN). Because of the unique expression of integrins on tumor exosomes it allows the preparations of PMN by the fusion with the resident cells inducing a pro-inflammatory environment with the activation of S100 in the future metastatic organ [20].

Different roles have been proposed for exosomes as diagnosis and therapy. For the diagnostic role, it is expected that they can offer a specific profile of molecules that could differentiate between cancers and to give more precise projection of the tumor development, so it can be used for liquid biopsies. The therapeutic role that has also been being evaluated, since exosomes have different profiles in different cancer, then if we could emulate an exosome for a specific cancer, it could be used to lead us to precision medicine.

\section{miRs and cancer}

Some of the molecules that have been widely studied present as exosomes cargo are miRs. miRs are single strands of RNA that are $\sim 20$ nucleotides long. miRs have the role to regulate mRNA transcription and translation, since it can silence a gene or bind to it which lead it to its degradation [13], and one miR can simultaneously target many mRNAs [21] and one mRNA can be target for many miRs.

The miRs have been proposed as markers for cancer, in fact, it has been observed that they reflect quite exactly the progression of the tumor, so it could be used as a tool to detect the prognosis, for example exosomes enriched with miR-23b-3p, miR-21-5p and miR$10 \mathrm{~b}-5 \mathrm{p}$ could be used as prognosis biomarkers in non-small cell lung cancer [22]. For example, miR-21 and miR-1225-5p levels are higher in exosomes of lavage peritoneal fluid from gastric cancer patients with high incidence of peritoneal metastasis compared to non-metastatic patients [23]. Another interesting miR is miR-320d, which could be used as a biomarker to differentiate between non-metastatic and metastatic colorectal cancer. What is more interesting is that miR$320 \mathrm{~d}$ was not associated with factors such as histological type, alcohol consumption, age or sex [24].

Resistance to chemotherapy molecules has been reported to be related to miRs delivered by exosomes, such as miR-96, to cisplatin resistance in lung cancer cells [25]. For breast cancer, miR-222 was related to resistance to adriamycin, miR-221/222 would also be promoting resistance to tamoxifen in ER positive breast cancer cells (MCF7) [26,27]. miR-base therapies could be a good tool, however the clinical trials did not achieve satisfactory effects [28].

${ }^{\star}$ Correspondence to: María Lorena Oróstica, Centro de Investigación Biomédica (CIB), Facultad de Medicina, Universidad Diego Portales, Santiago, Chile, E-mail: maria.orostica@mail.udp.cl

Key words: cancer, exosomes, therapy, miR

Received: April 03, 2021; Accepted: April 22, 2021; Published: April 26, 2021 


\section{Therapeutic targets}

Different types of therapies and different therapeutic targets have been sought to decrease tumor development and metastasis. Exosomes have been proposed as therapeutic targets, regulating their biogenesis, or using them as carriers of some drug for cancer therapy. Regarding the regulation of biogenesis, the Rab27 protein is involved in the biogenesis of exosomes, and it has been seen that the knockdown of this protein in mouse breast cancer cells, reduced the number of exosomes and inhibited metastasis in the lung [29]. Other Rab protein, Rab35, has been described as an oncoprotein since two somatic mutations can generate a constitutively active PI3K/AKT signalling, transforming cells in a PI3K-dependent manner, suppressing apoptosis [30]. The release of exosomes to the extracellular is dependent on calcium [31], and it was reported that a blocker of the $\mathrm{H}+/ \mathrm{Na}+$ and $\mathrm{Na}+/ \mathrm{Ca} 2+$ channels decreased the secretion of exosomes, decreasing the growth of cancer cells [32]. Therefore, regulating exosomal biogenesis has great potential, however, further research is needed to be able to have targets that are specific for the generation of carcinogenic exosomes.

Several systems have been studied as drug's delivery systems as based of natural and synthetic polymers or lipids, but even the last one can have a toxic response [33]. Then, exosomes are been tested as an engineering platform [34] because the can me be used as vectors for cancer therapy, as well as delivery of drugs, nucleic acid delivery (siRNAs, miRs), protein delivery (antigen, antibody) or cancer vaccines $[12,35]$, has been considered because they are biodegradable, nonimmunogenic, non-toxic and can be used for targeted therapy. It has even been proposed the use of plant-derived exosomes as carriers for drug delivery. Other benefits are: i) its charge can be delivered directly by cells or by sorting directly in the exosome; ii) different types of molecules can be loaded as proteins as genetic material; iii) protects the cargo from elimination or transformation before it reaches its target; and iv) are well tolerated by biological fluids [36]. An example of the use of exosomes as carriers is the delivery of doxorubicin to HER2+ cancer cells, and it was observed that those that were HER2+ captured these exosomes more efficiently than HER2- cells. As said before, gastrointestinal cancers are of interest since there still high incidence, and they also still have a high mortality rate. Exosomes are also being used as therapeutical molecules carriers in gastrointestinal cancers, and some examples are in table 1.

The use of exosomes has advantages such as their small size allowing it to penetrate organs that are protected by physiological barriers such as the blood-brain barrier and leukemic cells that have infiltrated the central nervous system can be attacked ${ }^{7}$. The use of exosomes as drugs carriers as doxorubicin, and it has been reported its antitumor activity [37]; as well in as delivery of paclitaxel prostate cancer cells showed enhanced cytotoxicity [38]. These examples show that the exosomedrug delivery could be a great for a safer therapy.

Table 1: Exosomes therapeutical uses in Cancers

\begin{tabular}{|c|c|c|}
\hline Gastrointestinal Cancer & Therapeutical use & Exosome Cargo \\
\hline Colorectal Cancer & $\begin{array}{l}\text { Immunomodulatory } \\
\text { functions }\end{array}$ & $\begin{array}{l}\text { Ascites-derived exosomes } \\
\text { combined with GM-CSF [42] }\end{array}$ \\
\hline \multirow{2}{*}{ Hepatocellula Cancer } & $\begin{array}{l}\text { Inhibits invasion and cell } \\
\text { growth in vitro }\end{array}$ & $\begin{array}{l}\text { Exosome with siRNA of GRP78 } \\
\text { and Sorafenib [43] }\end{array}$ \\
\hline & $\begin{array}{l}\text { Tumor suppression in } \\
\text { murine model }\end{array}$ & $\begin{array}{l}\text { Tumor-derived exosomes with } \\
\text { hepatocellular cancer antigens [44] }\end{array}$ \\
\hline \multirow{2}{*}{ Pancreatic Cancer } & $\begin{array}{l}\text { Suppressed cancer in } \\
\text { mouse models }\end{array}$ & siRNA or shRNA for KRAS [45] \\
\hline & $\begin{array}{l}\text { Increased survival in } \\
\text { mouse models }\end{array}$ & $\begin{array}{l}\text { Engineered exosomes targeting } \\
\text { oncogenic KRAS [46] }\end{array}$ \\
\hline
\end{tabular}

Another use of exosomes for liquid biopsies for cancer patients, since they are less invasive, and several studies have shown the potential of exosomal miRs as biomarkers [39], both could be an opportunity to develop personalized cancer treatment [40].

\section{Conclusions and perspectives}

Cancer still a public health system issue despite all the advances that have been done, probably because most of them do not have specific symptoms and there are mostly diagnosed in advances stages. Exosome's amount increases during pathologies as cancer, and it has been shown that they have a profile related to its cancer-origin. Because of these properties, exosomes are being proved to be used as biomarkers and as possible vaccines or cargo-delivery for cancer therapy. However, there still much until to do, since cancer is a heterogeneous disease, and each type of cancer should be treated as a unique one. Even more, exosomes are the safest way to deliver drugs because it is a nonsynthesized liposome then it is not rejected by the human body, and this is the most important feature for the drug-delivery to be done the most efficient and accurate way. But the most important objective of this kind of therapy is that allows to do personalized medicine, which it will significantly improve efficacy of therapy, since therapy as is done today it does not work in the same way to everybody.

Since exosomes are known to be enriched with molecules, this could be used to develop a profile for a specific cancer, and a molecule that could be used are miRs [41]. Then, miRs can been used as cargos for exosome-based therapy, since it can be a marker for cancers and cancers-development, and a miR profile that could be a tool for precision medicine.

There are a lot of expectations of these news technologies, named "engineered exosomes" that seems to be a great opportunity to develop new tools to deliver drugs and enhance its media life and capture by the target cancer cells.

\section{Acknowledgments}

The authors thank to Programa de Atracción e Inserción de Capital Humano Avanzado (PAI) from Agencia Nacional de Investigación y Desarrollo (ANID, Chile), grant No 77190041 (MLO).

\section{References:}

1. Rak J (2015) Organ-seeking vesicles. Nature 527: 312-314. [Crossref]

2. Kogure A, Yoshioka Y, Ochiya T (2020) Extracellular Vesicles in Cancer Metastasis: Potential as Therapeutic Targets and Materials. Int J Mol Sci 21: 4463. [Crossref]

3. Xin Z, Jiang S, Jiang P, Yan X, Fan C, et al. (2015) Melatonin as a treatment for gastrointestinal cancer: a review. J Pineal Res 58: 375-387. [Crossref]

4. Stem J, Flickinger JC Jr, Merlino D, Caparosa EM, Snook AE, et al. (2019) Therapeutic targeting of gastrointestinal cancer stem cells. Regen Med 14: 331-343. [Crossref]

5. Michael A, Bajracharya SD, Yuen PS, Zhou H, Star RA, et al. (2010) Exosomes from human saliva as a source of microRNA biomarkers: microRNA biomarkers in salivary exosomes. Oral Dis 16: 34-38. [Crossref]

6. Thind A, Wilson C (2016) Exosomal miRNAs as cancer biomarkers and therapeutic targets. J Extracell Vesicles 5: 31292. [Crossref]

7. Liu W, Bai X, Zhang A, Huang J, Xu S, et al. (2019) Role of Exosomes in Central Nervous System Diseases. Front Mol Neurosci 12: 240. [Crossref]

8. Soung Y, Ford S, Zhang V, Chung J (2017) Exosomes in Cancer Diagnostics. Cancers 9: 8. [Crossref]

9. Wang J, Hendrix A, Hernot S, Lemaire M, De Bruyne E, et al. (2014) Bone marrow stromal cell-derived exosomes as communicators in drug resistance in multiple myeloma cells. Blood 124: 555-566. [Crossref] 
10. Mathieu M, Martin-Jaular L, Lavieu G, Théry C (2019) Specificities of secretion and uptake of exosomes and other extracellular vesicles for cell-to-cell communication. Nat Cell Biol 21: 9-17. [Crossref]

11. Lobb RJ, Lima LG, Möller A (2017) Exosomes: Key mediators of metastasis and premetastatic niche formation. Semin Cell Dev Biol 67: 3-10. [Crossref]

12. Zhang X, Yuan X, Shi H, Wu L, Qian H, et al. (2015) Exosomes in cancer: small particle, big player. J Hematol Oncol 8: 83. [Crossref]

13. Ahmadi M, Rezaie J (2020) Tumor cells derived-exosomes as angiogenenic agents: possible therapeutic implications. J Transl Med 18: 249. [Crossref]

14. Peinado H, Zhang H, Matei IR, Costa-Silva B, Hoshino A, et al. (2017) Pre-metastatic niches: organ-specific homes for metastases. Nat Rev Cancer 17: 302-317. [Crossref]

15. Gordon MS, Mendelson DS, Kato G (2010) Tumor angiogenesis and novel antiangiogenic strategies: Tumor Angiogenesis and Antiangiogenic Strategies. Int $J$ Cancer 126: 1777-1787. [Crossref]

16. Sung BH, Ketova T, Hoshino D, Zijlstra A, Weaver AM (2015) Directional cell movement through tissues is controlled by exosome secretion. Nat Commun 6: 7164. [Crossref]

17. Ning X, Zhang H, Wang C, Song X (2018) Exosomes Released by Gastric Cancer Cells Induce Transition of Pericytes Into Cancer-Associated Fibroblasts. Med Sci Monit 24: 2350-2359. [Crossref]

18. Hoshino A, Costa-Silva B, Shen TL, Rodrigues G, Hashimoto A, et al. (2015) Tumour exosome integrins determine organotropic metastasis. Nature 527: 329-335. [Crossref]

19. Yen EY, Miaw SC, Yu JS, Lai IR (2017) Exosomal TGF- $\beta 1$ is correlated with lymphatic metastasis of gastric cancers. Am J Cancer Res 7: 2199-2208. [Crossref]

20. Liu Y, Cao X (2016) Characteristics and Significance of the Pre-metastatic Niche. Cancer Cell 30: 668-681. [Crossref]

21. Goodall GJ, Wickramasinghe VO (2021) RNA in cancer. Nat Rev Cancer 21: 22-36. [Crossref]

22. Liu Q, Yu Z, Yuan S, Xie W, Li C, et al. (2017) Circulating exosomal microRNAs as prognostic biomarkers for non-small-cell lung cancer. Oncotarget 8: 13048-13058. [Crossref]

23. Tokuhisa M, Ichikawa Y, Kosaka N, Ochiya T, Yashiro M, et al. (2015) Exosomal miRNAs from Peritoneum Lavage Fluid as Potential Prognostic Biomarkers of Peritoneal Metastasis in Gastric Cancer. PLoS One 10: e0130472. [Crossref]

24. Tang Y, Zhao Y, Song X, Song X, Niu L, et al. (2019) Tumor-derived exosomal miRNA-320d as a biomarker for metastatic colorectal cancer. J. Clin Lab Anal 33: e23004. [Crossref]

25. Wu H, Zhou J, Mei S, Wu D, Mu Z, et al. (2017) Circulating exosomal micrRNA-96 promotes cell proliferation, migration and drug resistance by targeting LMO7. $J$ Cell Mol Med 21: 1228-1236. [Crossref]

26. Xavier CPR, Caires HR, Barbosa MAG, Bergantim R, Guimarães JE, et al. (2020) The Role of Extracellular Vesicles in the Hallmarks of Cancer and Drug Resistance. Cells 9: 1141. [Crossref]

27. Wei Y, Lai X, Yu S, Chen S, Ma Y, et al. (2014) Exosomal miR-221/222 enhances tamoxifen resistance in recipient ER-positive breast cancer cells. Breast Cancer Res Treat 147: 423-431. [Crossref]
28. Grzywa TM, Klicka K, Włodarski PK (2020) Regulators at Every Step—How microRNAs Drive Tumor Cell Invasiveness and Metastasis. Cancers (Basel) 12: 3709. [Crossref]

29. Ostenfeld MS, Jeppesen DK, Laurberg JR, Boysen AT, Bramsen JB, et al. (2014) Cellular Disposal of miR23b by RAB27-Dependent Exosome Release Is Linked to Acquisition of Metastatic Properties. Cancer Res 74: 5758-5771. [Crossref]

30. Wheeler DB, Zoncu R, Root DE, Sabatini DM, Sawyers CL (2015) Identification of an oncogenic RAB protein. Science 350: 211-217. [Crossref]

31. Savina A, Furlán M, Vidal M, Colombo MI (2003) Exosome Release Is Regulated by a Calcium-dependent Mechanism in K562 Cells. J Biol Chem 278: 20083-20090. [Crossref]

32. Chalmin F, Ladoire S, Mignot G, Vincent J, Bruchard M, et al. (2010) Membraneassociated Hsp72 from tumor-derived exosomes mediates STAT3-dependent immunosuppressive function of mouse and human myeloid-derived suppressor cells. $J$ Clin Invest 120: 457-471. [Crossref]

33. Farooqi AA, Desai NN, Qureshi MZ, Librelotto DRN, Gasparri ML, et al. (2018) Exosome biogenesis, bioactivities and functions as new delivery systems of natura compounds. Biotechnol Adv 36: 328-334. [Crossref]

34. Steeg PS (2016) Targeting metastasis. Nat Rev Cancer 16: 201-218. [Crossref]

35. Kim YK, Choi Y, Nam GH, Kim IS (2020) Functionalized exosome harboring bioactive molecules for cancer therapy. Cancer Lett 489: 155-162. [Crossref]

36. Wei H (2021) Regulation of exosome production and cargo sorting. Int J Biol Sci 17: 163-177. [Crossref]

37. Patil SM, Sawant SS, Kunda NK (2020) Exosomes as drug delivery systems: A brief overview and progress update. Eur J Pharm Biopharm 154: 259-269. [Crossref]

38. Saari H, Lázaro-Ibáñez E, Viitala T, Vuorimaa-Laukkanen E, Siljander P, et al. (2015) Microvesicle- and exosome-mediated drug delivery enhances the cytotoxicity of Paclitaxel in autologous prostate cancer cells. J Controlled Release 220: 727-737. [Crossref]

39. Yoshioka Y, Katsuda T, Ochiya T (2018) Extracellular vesicles and encapusulated miRNAs as emerging cancer biomarkers for novel liquid biopsy. Jpn J Clin Oncol 48 869-876. [Crossref]

40. Choi D, Lee TH, Spinelli C, Chennakrishnaiah S, D'Asti E, et al. (2017) Extracellular vesicle communication pathways as regulatory targets of oncogenic transformation. Semin Cell Dev Biol 67: 11-22. [Crossref]

41. Haraszti RA, Didiot MC, Sapp E, Leszyk J, Shaffer SA, et al. (2016) High-resolution proteomic and lipidomic analysis of exosomes and microvesicles from different cell sources. J Extracell Vesicles 5: 32570. [Crossref]

42. Dai S, Wei D, Wu Z, Zhou X, Wei X, et al. (2008) Phase I Clinical Trial of Autologous Ascites-derived Exosomes Combined With GM-CSF for Colorectal Cancer. Mol Ther 16: 782-790. [Crossref]

43. Li H, Yang C, Shi Y, Zhao L (2018) Exosomes derived from siRNA against GRP78 modified bone-marrow-derived mesenchymal stem cells suppress Sorafenib resistance in hepatocellular carcinoma. J Nanobiotechnology 16: 103. [Crossref]

44. Rao Q, Zuo B, Lu Z, Gao X, You A, et al. (2016) Tumor-derived exosomes elici tumor suppression in murine hepatocellular carcinoma models and humans in vitro: HEPATOBILIARY MALIGNANCIES. Hepatology 64: 456-472. [Crossref]

45. Kamerkar S, LeBleu VS, Sugimoto H, Yang S, Ruivo CF, et al. (2017) Exosomes facilitate therapeutic targeting of oncogenic KRAS in pancreatic cancer. Nature 546: 498-503. [Crossref]

46. Mendt M, Kamerkar S, Sugimoto H, McAndrews KM, Wu CC, et al. (2018) Generation and testing of clinical-grade exosomes for pancreatic cancer. JCI Insight 3: e99263. [Crossref]

Copyright: (C2021 Retamales-Ortega R. This is an open-access article distributed under the terms of the Creative Commons Attribution License, which permits unrestricted use, distribution, and reproduction in any medium, provided the original author and source are credited. 